Chapter 12

\title{
Eco-Engineering and Protection Forests Against Rockfalls and Snow Avalanches
}

\author{
Frédéric Berger, Luuk Dorren, Karl Kleemayr, \\ Bernhard Maier, Spela Planinsek, Christophe Bigot, \\ Franck Bourrier, Oliver Jancke, David Toe and \\ Gillian Cerbu
}

Additional information is available at the end of the chapter

http://dx.doi.org/10.5772/56275

\section{Introduction}

The primary function considered to be of economic importance for forest stands has always been wood production. Today, society is aware of the necessity of forests' provision of additional functions: tourism, outdoor activities, fauna and flora protection, biodiversity, etc. In mountain areas, forests can also serve a protective function against natural hazards.

Many forests in the Alps cover steep to very steep slopes (gradients of 35 - 70 degrees) and so have an important protective function against natural hazards, such as: rockfall, snow avalanches, shallow landslides and erosion. The primary function of protection forests is to protect people or assets against the impacts of natural hazards. In order to provide this function,, the first 'products' of these forests are standing trees. Trees act as obstacles to mass movement hazards and/or to the propagation downslope of these hazards (within the MANFRED project we have focused on rockfall and snow avalanche risks). In the European Alps, mountain forests and the protection they provide have a long and distinguished history. This function has been recognized for centuries, as evident from logging bans declared from $\sim 1350$ onwards. However, in the last few decades, forest management has shifted its focus from timber management to multiple uses and forest ecosystem management. During this transition, there has been an increasing awareness of the need to manage the multiple functions of mountain forests aside from production and protection.

This protective function is also clearly identified in the first paragraph of the Mountain Forest Protocol of the Alpine Convention of 1996: "mountain forests ...provide the most effective, the 
least expensive and the most aesthetic protection against natural hazards." In Austria and Switzerland alone, approximately 50 million $€$ are spent yearly to maintain or improve the protection provided by mountain forests $[1,2]$.

In order to sustain the protective effect of these forests, they often have to be managed. Traditionally, mountain forests have been exploited for their timber and non-timber products, with the exception of forests on slopes above residential areas that present active natural hazards. A transition in forest management has occurred due to the increasing use of mountain areas and the diversification of Alpine economies, which have evolved from agricultural to tourism-based economies. During recent decades the damage potential, and therefore the importance of protection forests, has increased. Remote mountainous areas that were formerly avoided over the winter are now expected to be permanently and safely accessible to tourists. Moreover, settlements have been spreading into areas that were considered unsafe in the past, and infrastructure crossing the Alps (roads, power-lines, etc.) has greatly increased [3]. Thus, forests traditionally designated as protection forests have now gained wider recognition due to their increasing importance as well as their direct economic and social benefits [4]. The protective effect of forests against geo-hazards such as rockfalls and snow avalanches cannot be neglected in risk management. Furthermore, forest cover is constantly evolving, and targeted silviculture strategies are needed to maintain or increase forests' protective role. For this reason protection forest management has evolved with time from doing nothing ('banned forests'), to strictly silvicultural based management, e.g., selective cuttings to create openings in dense forests for the promotion of regeneration, to ecological engineering in mountain forests.

\section{Eco-engineering: Definition and concepts}

The term "ecological engineering" was originally described by Odum at the beginning of the 1960s, as "the management of nature" [5]. In the 90s, Mitsch and Jorgensen (see [5]) largely worked on this concept and finally defined it as "the design of sustainable systems, consistent with ecological principles, which integrate human society with its natural environment for the benefit of both" (see [5]). Bergenetal.In2001 insiston theneed forecologicalengineering practices to be based on the science of ecology(see [5]). They also expand this to include all types of ecosystems and interactions between man and nature. More recently, Jones et al. highlighted the ethical, relational and intellectual dimensions of ecological engineering, therefore distinguishing it from environmental engineering, as explained before by Allen et al. (see [5]). Adapted eco-engineering practices are required to provide forests' ecosystems services over the longerterm including: timber production, wildlife habitat, water quantity and quality, hazard protection, recreation, inter alia that support quality of life and human well-being. Applying eco-engineering concepts can help to both protect forests and benefit humans.

Within the MANFRED project, eco-engineering refers to a mix of silvicultural measures and strategic creation of dead wood barriers such as higher left stumps and diagonally-placed felled tree stems on slopes. If required, real avalanche or rockfalls barriers can be also con- 
structed with locally-felled wood. These actions mitigate natural hazards and promote forest renewal, enabling the forests to remain in a vital, stable state. Before eco-engineering practices are implemented, a series of analyses have to be carried out to determine the types, magnitudes and frequencies of the natural hazards that occur on site. Secondly, the current protective capacity of the forest has to be assessed. Thirdly, the developmental stage of the forest along with its future evolution will have to be evaluated. This evaluation needs to take into account the probable consequences of climate changes on both natural hazards and tree species' geographical distributions. Consequently, if the degree of protection does not suffice or tends to decrease in the future and if the forest has a potential for optimising its protective function, human intervention using eco-engineering can be a good option.

To support these interventions, protection forest researchers have been developing indicators and target values for specific mountain forests with different protective functions. Increasingly, the protective functions of mountain forests need to be evaluated alongside other functions and uses. This is difficult as foresters and forest researchers are still determining the characteristics of a forest that can provide optimal protection. Knowledge is limited due to the slow reaction of natural forests to the rapid environmental and socio-economic changes that have occurred in the Alps over the past 100 years. Fortunately, there has been considerable progress in research and practice on both the protective effect of forests against natural hazards as well as on the management of protection forests. The combination of this knowledge and experience provides a basis for balancing tradition and technology. This work resulted in practical guidelines in Switzerland, France and Italy as well as a variety of analysis tools for managing protection forests.

However, even if eco-engineering and silvicultural concepts, along with practical guidelines are based on forest ecosystems' natural cycles, adopting this type of management is impossible on all mountain forests due to financial restrictions. In this context, the knowledge of the spatial distribution of these protection forests and their differing abilities in preventing natural hazards becomes essential. Recognizing that forests offer protection against rockfall and snow avalanches is one matter, quantifying this effect is another one.

The three main objectives of the MANFRED project in the field of protection forest management in light of a changing climate have been to: 1) select and test a methodology for protection forest mapping, 2) propose an operational synthesis of protection forest management guidelines and, 3) upgrade these guidelines by integrating the findings from this project.

\section{A methodology and tools for the mapping of protection forest against rockfall and snow avalanches}

A forest has a protective function only if it protects society and facilities from hazards. Stemming from this, the 3 most important topics for protection forest mapping are: hazards, human infrastructure (at risk) and forests. This mapping can be done, depending on objectives of the exercise, at different scales. The regional scale is traditionally used for strategic forest planning and management, and the local scale (watershed, versant/slope, corridor) applied 
for silvicultural treatment. Mapping at the regional scale can be performed without accurate forest data; however, this is not the case for the local scale. In order to analyse the potential consequences of climate change on forests' protection function, here we have decided within to use a regional scale for analysis in order to use the same scale as the tree species distribution maps produced for the project. These maps are at the scale of the European Alpine Space with a resolution of $1 \mathrm{~km} 2$.

The first regional protection forests for testing methodologies to combat snow avalanches and rockfall have been conceptualized in prior European projects: Rockfor, Provialp, Proalp and IFP. The general principle for this mapping is based on answering the following questions (Figure 1):

1. Where are the release areas?

2. What is the maximum propagation area envelope?

3. Is any human infrastructure located in the propagation area and if so, is it endangered?

4. Are any forest stands located in the release area and/or in the propagation area above the human infrastructure endangered?

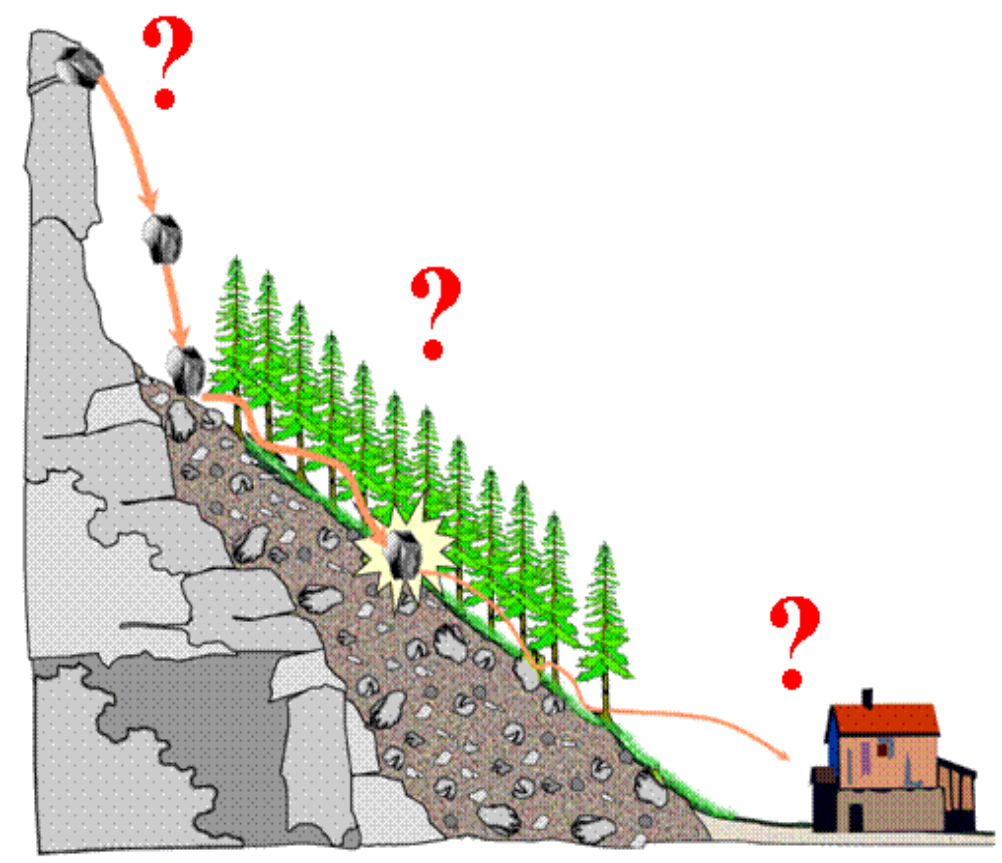

Figure 1. Schematic representation of the main questions to be addressed in mapping of protection forest for rockfall protection: Where are the release zones?, what is the maximum envelope of propagation, is there any infrastructure endangered and what is the role play by forest stands? 
If the answer to the last question is yes, these forest stands serve a protective function, and an investigation at the scale of the stand is needed in order to qualify and/or quantify the efficiency of this protection.

\subsection{Rockfall and snow avalanche potential maximal envelope of propagation mapping}

The advantage of the regional scale is that models for identifying potential release and propagation zones can be used which do not requiring meteorological or geological data. The advantage of these models based on topographic criteria is that the only input datum is a digital terrain model. The calibration of these models has been made within the Interreg Alpine Space project Paramount. These models are: AvalForLIN for snow avalanches and RockForLIN for rockfalls. They have been developed by the French research centre, IRSTEA, and used to develop a method for protection forest mapping using Geographic Information Systems (GIS).

Firstly, all potential release points have to be mapped. 2D GIS models have been developed to localize these dependent on topographic conditions:

1. For rockfall, a simple slope threshold is applied to the slope surface raster (computed from the raster Digital Elevation Model [DEM]), according to the equation: $\alpha=55^{\circ} \times \mathrm{RES}^{-0.075}$, where RES is the DEM resolution. All cells with values higher than the threshold $\alpha$ are qualified as potential release zones for rock fall.

2. For snow avalanches, curvature, slope, attitudinal and area criteria are chosen, depending on regional and geo-climatic conditions. Commonly in the European Alps, all cells in the raster with a slope of 28- 55 degrees, a convex form, a $>1000 \mathrm{~m}$ altitude and $>500 \mathrm{~m}^{2}$ area are considered as potential release zones for avalanches.

Following, from each of the identified potential release points, 2D GIS models simulate the probable run out envelopes:

1. RockForLIN for rockfalls is based on the Energy Line principle [6], and can be used to compare rockfalls' run out envelopes to slope angles (Figure 2). The maximum spread of a block is determined by intersecting the ground and an imaginary line drawn from the release point with angle $\beta$. Different values for $\beta$ were used: 32,35 and $38^{\circ}$. Areas between 32 and $35^{\circ}$ have a low but not 0 probability to be reached by rockfalls; between 35 and $38^{\circ}$, an intermediate probability; and higher than $38^{\circ}$, a high probability.

2. AvalForLIN for avalanches is also based on the Energy Line principle [7] (Figure 3). The maximal probable run out envelope is determined by the creation of an intersect between the ground and an imaginary line drawn from the release point with a calibrated angle. This angle is determined using the value of the energy line angle calculated for the point for which the slope angle is equal to $10^{\circ}$. AvalForLIN angles have been calibrated using snow avalanche cadastres (F, A, I, SLO). 


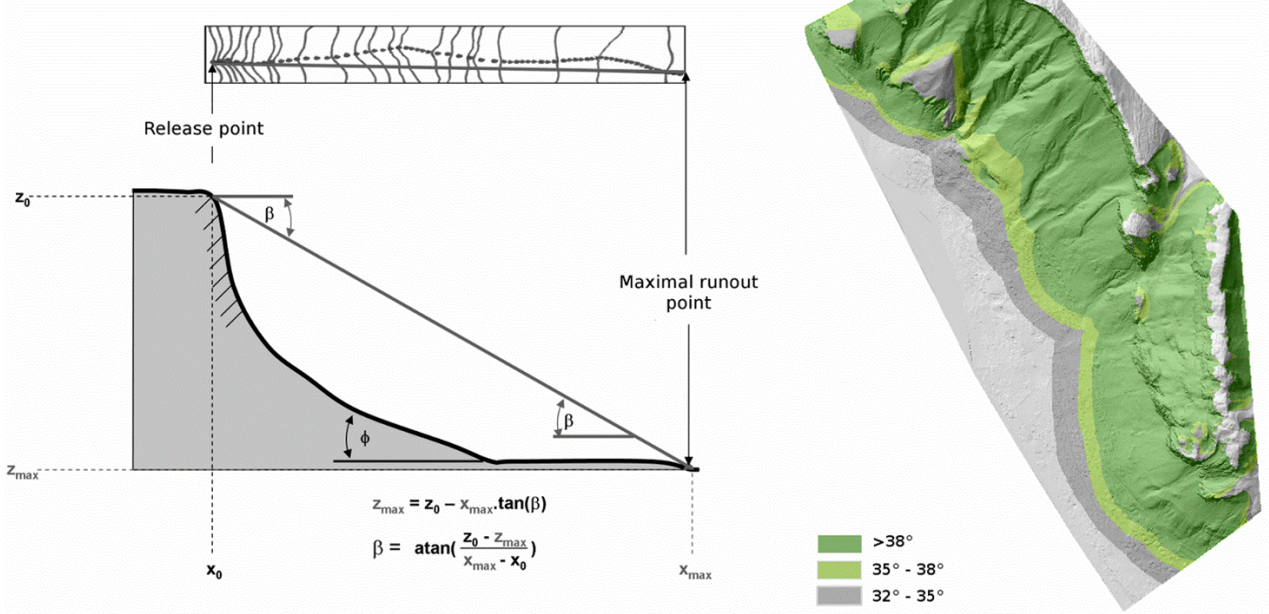

Figure 2. Rockfall Energy Line Principle and an example of a result obtained with it.

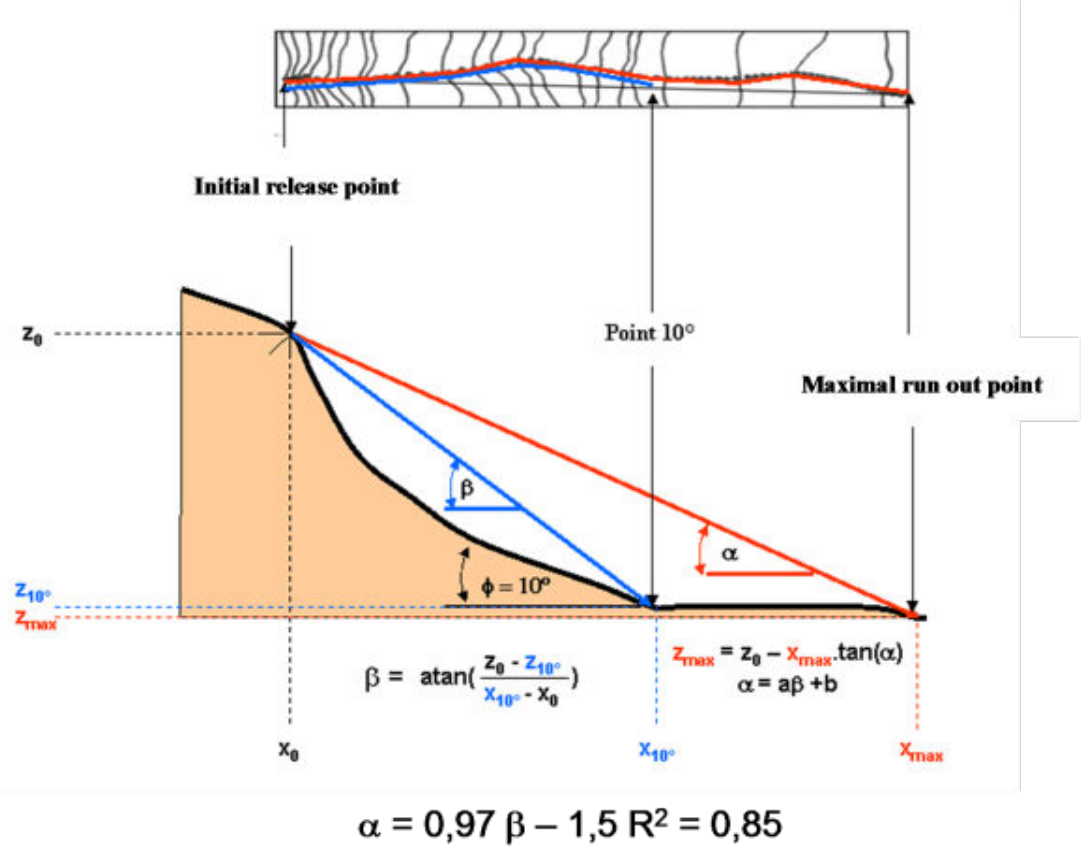

Figure 3. Snow avalanches Energy Line Principle and the values of the model for the French Northern Alps. 


\subsection{Human infrastructure and protection forest mapping}

Good information on the location of facilities is required to classify forests' protective functions and organize priority blocks for forest actions. At a regional scale, each of the Alpine Space countries can find this information in the geographic database of their respective national geographic institutes. Usually these databases list and correspondently map all human infrastructure: public facilities, dwellings, industries, as well as communication, electrical, gas and water infrastructure, etc. According to their importance or their extent, all items can be classified into 4 protection priority levels, from 0: low to 3: high level. This ranking is not obligatory, but facilitates the definition of priority levels for specific silvicultural actions depending firstly on the importance of the issues and secondly on forest stability. This ranking is required to be performed jointly with all actors involved in risk prevention policy of the study area.

By combining this map with the hazard run out envelope map, the potentially endangered infrastructure can be identified by selecting all the items located between release points and run out envelopes. The map obtained includes the endangered issues and the associated release and run out zones.

The last step of the process is then to cross this map of endangered issues with the map of the geographical extension of forest stands. This forest map can be the one provided by National Forest Inventories or the one available in the forest services. As the mapping is made at a regional scale, the dendrometrical description of the forest stands is not required. The information required is that of the surface covered by forest. Identification of forest stands potentially serving a protection function is then obtained by combining the endangered items map with the forest cover map, and by selecting all forested areas located above an endangered item and on/or between the associated release and run out zones.

This map of potential protection forest areas is required to be validated by a field survey. But before this, it can be used to define an area within which forest management dedicated to the improvement of the protection function needs to be applied. In other terms, this map defines the potential area of use of protection forest management guidelines. By using this methodology and these tools, policy- and decision- makers can then provided an efficient comparison between different regions.

The strength of this methodology lies in its ability to display the area within which forests are able to provide a protective function against rockfall and/or snow avalanches; often such areas are unknown having not been previously identified. A decrease in forest canopy in these protection forest areas could have dramatic consequences requiring adaptations to forest management to ensure the sustainability of this protective function.

Using this method, $43 \%$ of forests in Switzerland have a protective function, $42.7 \%$ in Val d'Aosta, and $29.5 \%$ and $24.7 \%$ in the French departments of Haute-Savoie (Figure 4 ) and Isère. In Austria and Germany, the area of forest providing a protective function is at $25 \%$ in Austria and of $34 \%$ in Germany. In Slovenia the only data available are for forests officially classified as protection forests: $9 \%$ of the forested area. For the Northern part of the Alpine Space, protection forests make up $\sim 33 \%$ of the total forest cover. 


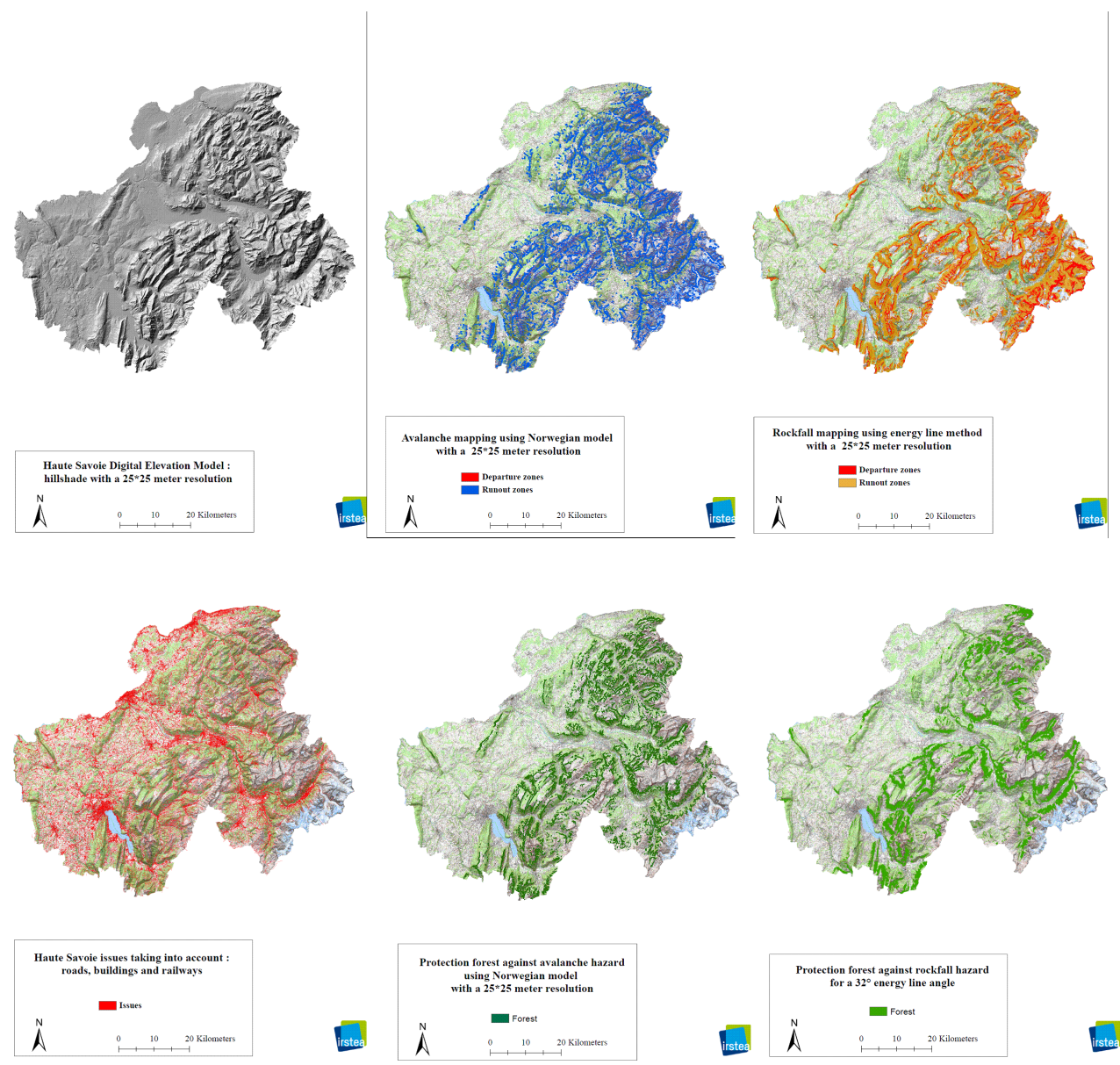

Figure 4. The principle steps for protection forest mapping. The example of the French Department of Haute-Savoie (one of the pilot area of the project MANFRED) : the Digital Terrain Model, the snow avalanche mapping results, the rockfall mapping results, the human infrastructure map, the forest's protection function in snow avalanche prevention, the forest's protection function in rockfall prevention

\section{Silvicultural recommendations for the management of snow avalanche and rockfall protection forest}

Protection forests act as natural obstacles which avoid or limit snow avalanche release and rockfall propagation. This protective function is created by the trunk and the crown of the trees present in these forests. In order to ensure the efficiency and the sustainability of this function, such forests have to be managed to ensure a stable and continuous forest cover. In other terms, 
silvicultural systems used and any natural disturbances that occur need to leave a sufficient amount of forest cover intact to maintain this protective function. Thus forest management plans have to be designed to take into consideration a long-term perspective for sustainable risk mitigation and the implementation of optimized management for protection forests. As concerns other forests, the primary objective of forest management should be ensuring the regeneration of forest stands. In the case of mountain forests, foresters have to create gaps to facilitate regeneration. Cutting trees may seem paradoxical in protection forests but is however necessary. In the context of risk prevention, these openings have to meet specific criteria to limit the negative impacts of cutting trees in protection forests. In order to help foresters define such adapted protection forest management, the consortium of the MANFRED project proposes a list of silvicultural recommendations and prescriptions. For the main silvicultural criteria, this list gives the thresholds values which facilitate the optimal protective effect of forest stands. These thresholds are mentioned in the synthesis of the guidelines currently used in the Alpine Space $[8,9,10]$ and based on the expert knowledge contributed within the MANFRED project.

\section{The use of stumps and felled trees in eco-engineering}

In Austria, but also increasingly in Switzerland, France and Italy, the effects of the presence of couloirs or larger openings in protection forests are mitigated by cutting trees and 1) cutting tree stems during harvesting as high up as possible (leaving tree stumps at height of $>1.3 \mathrm{~m}$ ) and 2) positioning the felled stems on the slope diagonal to the slope direction. Important criteria for selecting the trees to be cut are: the position and the growth tendency with respect to the corridor, the DBH (thicker stems, or if possible multiple trunks on top of each other, are clearly more effective barriers and should be left), tree instability, the effect on tree regeneration, the size of the gaps after cutting, as well as the shadow effect. The shadow effect is the phenomenon of in protection forests, of trees growing behind each other, or younger trees tending to grow downslope of older trees; i.e., the older tree protects younger trees downslope [11].

Another important aspect is the direction in which the felled trunk is positioned on the slope. In snow avalanche release zones trunks should be placed perpendicular to the steepest slope direction. One of the most important points is that these felled trees have to be kept in place on the slope in order to avoid any displacement or mobilization due to snow gliding or to the impact of a snow avalanche.

In the case of rockfall, a choice can be made to direct all rocks away from a channel, preferably into areas with a high stand density or a high surface roughness (e.g., depressions where many larger rocks have been deposited). Alternatively, if the corridor has become a real channel, in which forest regeneration is inhibited, all rocks can be directed into this channel by using accurately-positioned felled trunks that orient rocks towards this channel. A precondition for the latter case would be that there is sufficient protection at the end of the corridor, i.e. a rockfall net or rockfall dam. 


\begin{tabular}{|c|c|c|}
\hline & Recommendations & Thresholds \\
\hline \multirow{9}{*}{ Release zone } & Remove unstable trees & Coefficient of stability value \\
\hline & & (Height/Diameter at breast height = H/D) \\
\hline & & Coniferous: $\mathrm{H} / \mathrm{D} \leq 65$ \\
\hline & & Broad-leaves: $\mathrm{H} / \mathrm{D} \leq 80$ \\
\hline & $\begin{array}{l}\text { The following effects: interception of } \\
\text { increasing soil roughness, are efficien } \\
\text { height of the snow cover. }\end{array}$ & $\begin{array}{l}\text { snowfall, anchoring of the snowpack by punching, } \\
\text { t when the height of the trees is twice higher than the }\end{array}$ \\
\hline & $\begin{array}{l}\text { On the edges of gaps obtain trees wit } \\
\text { of the height of the tree) }\end{array}$ & h the greatest crown length as possible (more than $2 / 3$ \\
\hline & $\begin{array}{l}\text { Limit the proportion of deciduous } \\
\text { trees and larch }\end{array}$ & $\begin{array}{l}\text { Presence of deciduous trees should be maintained at } \\
<30 \%\end{array}$ \\
\hline & $\begin{array}{l}\text { Depending on the ecological conditic } \\
\text { the stability of stands }\end{array}$ & ns, a certain amount of broad-leaves are needed for \\
\hline & $\begin{array}{l}\text { Deciduous trees are more suitable for } \\
\text { smaller quantities of snow allowing } \mathrm{m} \\
\text { snow. With large quantities of snow } t \\
\text { ground enable good sliding which ca }\end{array}$ & $\begin{array}{l}\text { the prevention of snow gliding during periods of } \\
\text { hore sunlight to reach the canopy floor and melt the } \\
\text { heir effect is negligible. Fir and spruce needles on the } \\
\text { n cause avalanches. }\end{array}$ \\
\hline \multirow{16}{*}{$\begin{array}{l}\text { Transit and run out } \\
\text { zones }\end{array}$} & $\begin{array}{l}\text { Limit gap size } \\
\text { (same thresholds as for transit and } \\
\text { run out zones) }\end{array}$ & $\begin{array}{l}\text { Length of gap (measured on the slope) along the line } \\
\text { of the steepest slope } \\
\text { ( } \mathrm{H}=\text { average height of trees) } \mathrm{L} \leq 1.5 \mathrm{H} \\
\text { The gap width }<15 \mathrm{~m}\end{array}$ \\
\hline & $\begin{array}{l}\text { Maintain an effective winter canopy } \\
\text { cover }\end{array}$ & $\begin{array}{l}\text { Value of the canopy cover in winter according to the } \\
\text { slope (in }{ }^{\circ} \text { ) }\end{array}$ \\
\hline & & $30^{\circ}>30 \%$ \\
\hline & & $35^{\circ}>50 \%$ \\
\hline & & $40^{\circ} \&$ more $>70 \%$ \\
\hline & \multicolumn{2}{|c|}{$\begin{array}{l}\text { Harvest trees leaving stumps with a min. height of } 1.30 \mathrm{~m} \text { or, if rockfall can occur, completely } \\
\text { remove stump to ground-level (or screed in order to avoid a trampoline effect). }\end{array}$} \\
\hline & \multicolumn{2}{|c|}{$\begin{array}{l}\text { Fell/cut trees at an oblique angle to the slope leaving felled trees on the ground in a position } \\
\text { that they cannot be easily moved. }\end{array}$} \\
\hline & Limit gap size & (same threshold as release zone) \\
\hline & $\begin{array}{l}\text { Promote stable deciduous trees to } \\
\text { limit the effect of powder } \\
\text { avalanches (decrease forest canopy } \\
\text { permeability) }\end{array}$ & $\begin{array}{l}\text { Corridor edge } \geq 70 \% \text {, } \\
\text { otherwise }>30 \%\end{array}$ \\
\hline & Remove unstable trees along & Coefficient of stability value \\
\hline & corridors & (Height/Diameter at Breast Height = H/D) \\
\hline & & Coniferous: $\mathrm{H} / \mathrm{D} \leq 65$ \\
\hline & & Broad-leaves: $\mathrm{H} / \mathrm{D} \leq 80$ \\
\hline & \multicolumn{2}{|c|}{$\begin{array}{l}\text { Harvest trees leaving stumps with a min. height of } 1.30 \mathrm{~m} \text { or, if rockfall can occur, completely } \\
\text { remove stump to ground-level (or screed in order to avoid a trampoline effect). }\end{array}$} \\
\hline & \multicolumn{2}{|c|}{ Do not leave deadwood (i.e. logs) on the forest floor. } \\
\hline & \multicolumn{2}{|c|}{ Remove trees that, when they fall, can reach issues } \\
\hline
\end{tabular}

Table 1. Silvicultural recommendations for the sustainable mitigation of snow avalanches by forest stands 


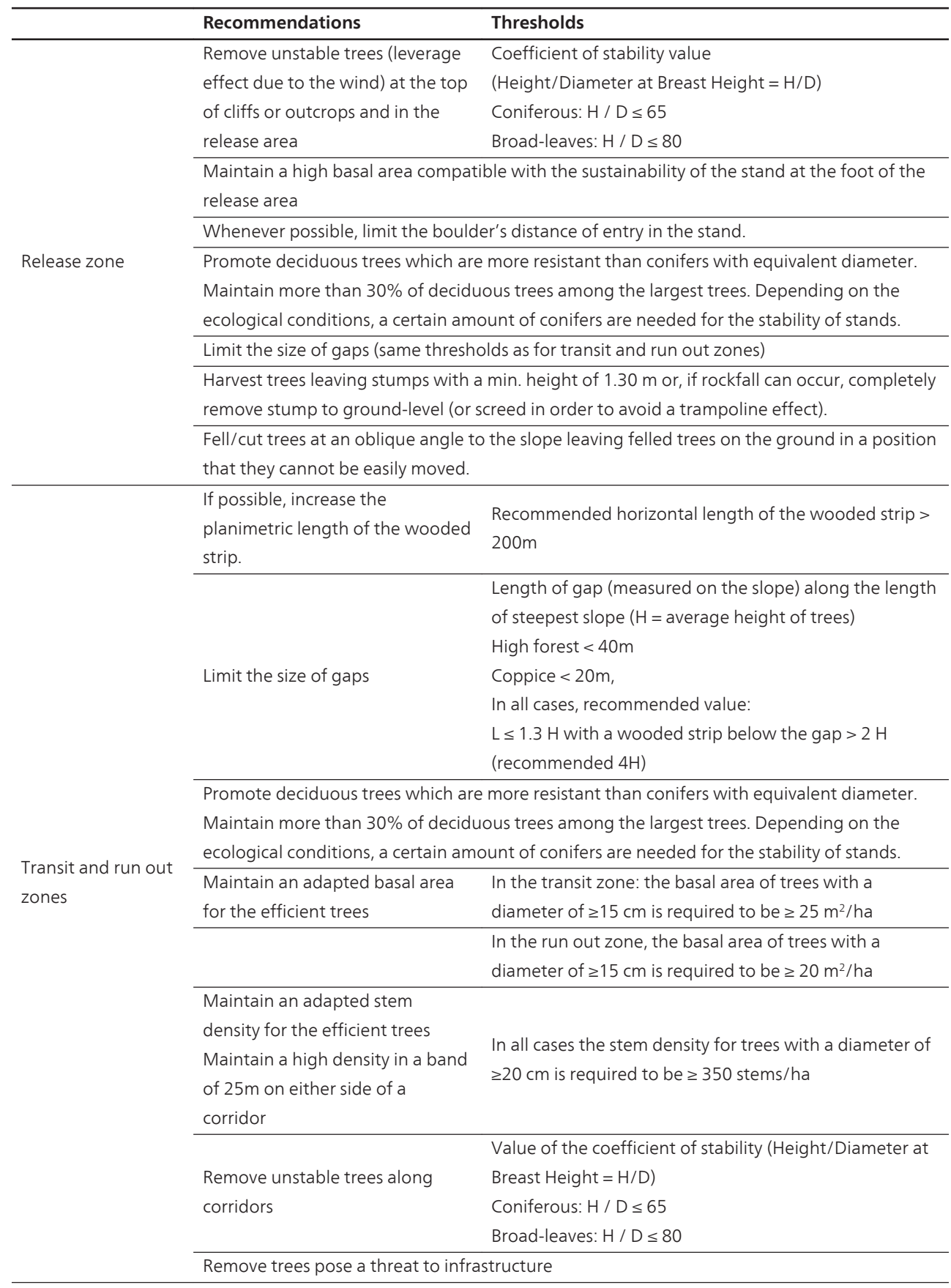

Table 2. Silvicultural recommendations for rockfalls sustainable mitigation by forest stands 
To test the efficacy and durability of such diagonally felled trees, within the MANFRED project specific research actions have been carried out in which 1) experiences from practitioners as well as resistance measurements on the durability of felled stems were collected and 2) fullscale rockfall experiments on felled stems conducted.
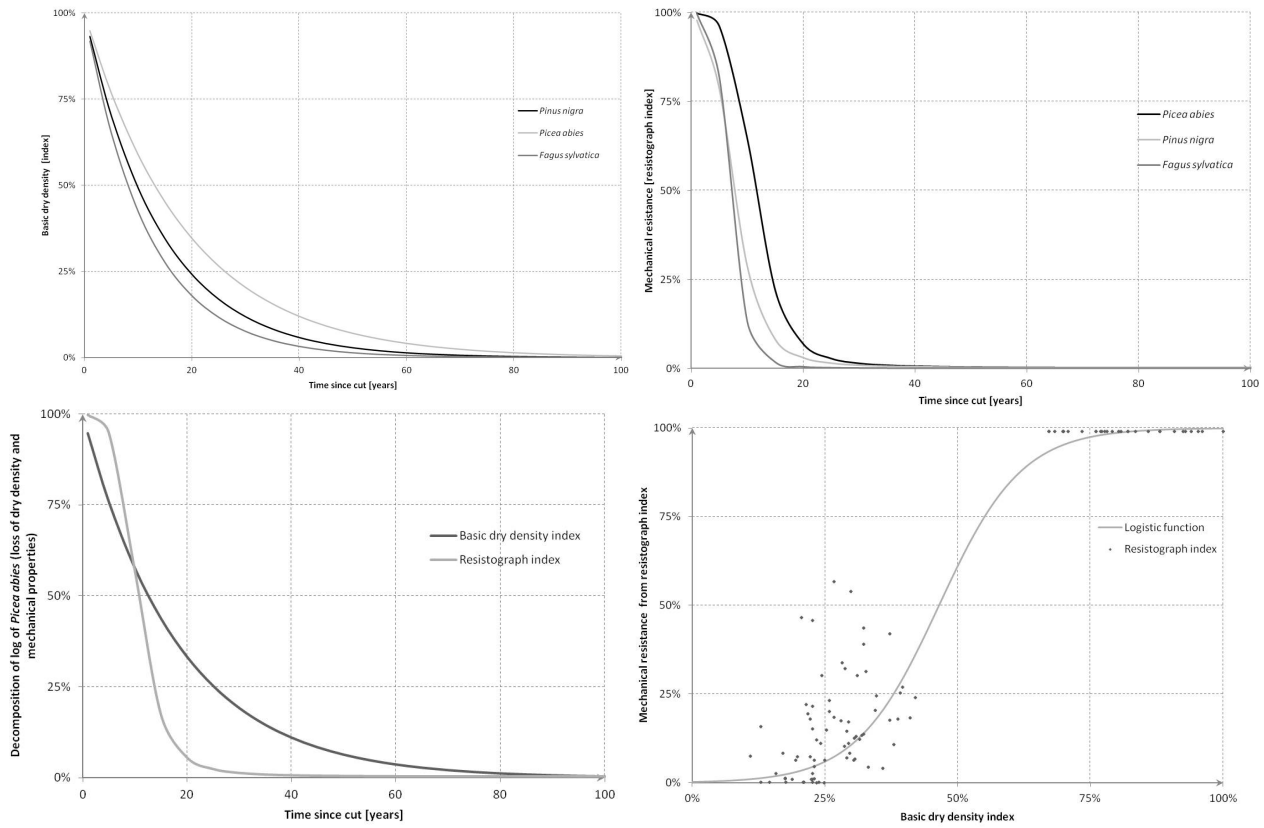

Figure 5. Graphical representations of the breaking dynamics of Picea abies (dark line), Fagus sylvatica (gray line) and Pinus nigra (soft grey line) relative to wood decay and its consequences on the loss of dry densities (stumps) and mechanical properties (stumps, log ). The last graph represents the sigmoidal correlation between the loss of dry density and the loss of mechanical properties for Picea abies stumps. The loss of the mechanical properties has been measured using a resistograph. 
The research has further shown that the felled trees have a significant effect on the energy loss ( $30 \%$ on average during an impact on a felled stem) and on the fall direction of the rock. If all the stems are oriented in the same direction, laboratory experiments showed that the rock will also change its direction. The results also indicate that the most optimal orientation of the stems would be between $45^{\circ}-70^{\circ}$ less than the steepest slope direction (slope aspect) (Figure 6).

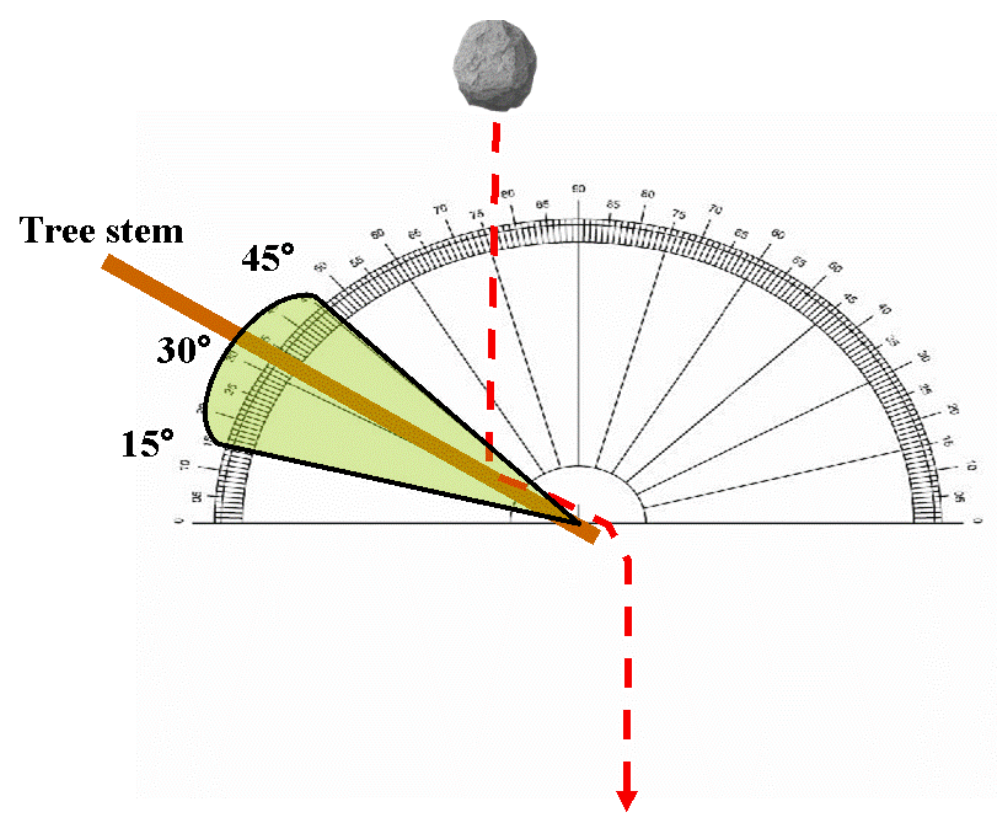

Figure 6. Representation of the range of optimal angles (green zone) for stems positioned obliquely to the steepest slope direction or the main fall direction of the rocks (dashed line).

\section{Marteloscope: Definition, concepts and uses}

Marteloscopes are training plots (approx. 1 ha) in protection forests where forest practitioners are asked to (virtually) manage the present forest in the best way to obtain an optimal long term protection function. They are asked when and how to apply silvicultural methods. After that, the notes of every participant are processed by a coupled growth dynamics (SAMSARA, PNN2) and protection function simulation model (for rockfalls: Rockyfor3D or RockforNet, for snow avalanches: SnowForIntercept). The next day, the best and other management options are discussed, especially in the light of the local context of the forest (ecological, economical and social functions). 
The main objective of a marteloscope is therefore the training and education of forest practitioners.

There are multiple techniques involved in establishing a marteloscope. The first step is to select the plot. The plot's characteristics are the following: 1 ha $(100 \times 100 \mathrm{~m}$ planimetric), uniform relief and slope, all trees $\geq 7.5 \mathrm{~cm}$ DBH must be recorded and their situation defined by absolute XYZ distances from the lower left corner of the plot. The selection of the site must be performed using the following check-list:

- Easy accessibility: Reasonable distance by car, Max. 30 min walking distance from the parking

- Infrastructure: Parking of adequate size, reasonably-priced accommodations nearby.

- Risk situation: The site should be situated in the transit zone of a real risk situation (greater scientific interest; far more demonstrative for the practitioners).

- Forest: Uniform characteristics on the entire marteloscope surface $( \pm 1$ ha), the relief should also have uniform characteristics, it should be representative for a typical or specific forest type, the local context of the forest should be considered (ecological, economical and social functions).

- Data:It is advantageous if forest data is already available; i.e. information on previous forest management, regions where LiDAR or high resolution DEM data is available should be preferred, meteorological data, past events database.

- Safety: The safety of the practitioners should be considered (limited "exposition" time, limited number of persons, helmets etc.) as the safety of the issues located below the plot.

The choice of the procedure for mapping the trees is largely depending on the forest characteristics, on the available technical equipment and on the habits/competences of the field workers. It is possible with a compass, a clinometer and a decameter, but it will be faster and more precise using ultrasound or laser measuring devices or even a theodolite and high precision GPS.

9 marteloscopes have been implemented and used within the lifetime of the MANFRED project: 2 in France, 2 in Austria, 4 in Slovenia and 1 in Switzerland. Two sites deal with protection forest management against snow avalanches release and 7 with protection forest management in order to mitigate rockfall propagation. Four are covered by pure beech stands, 1 by a mixed stand of beech and silver fir, 1 with a pure Austrian black pine stand and 3 with pure spruce stands. All the data are available on MANFRED'S website. The figure below presents schematic representations of some of these training plots.

Within the framework of the activities of the MANFRED project, these 9 marteloscopes have served as a database for international know-how and knowledge exchange, as well as cases for the revision of regional protection forest recommendations and prescriptions. 


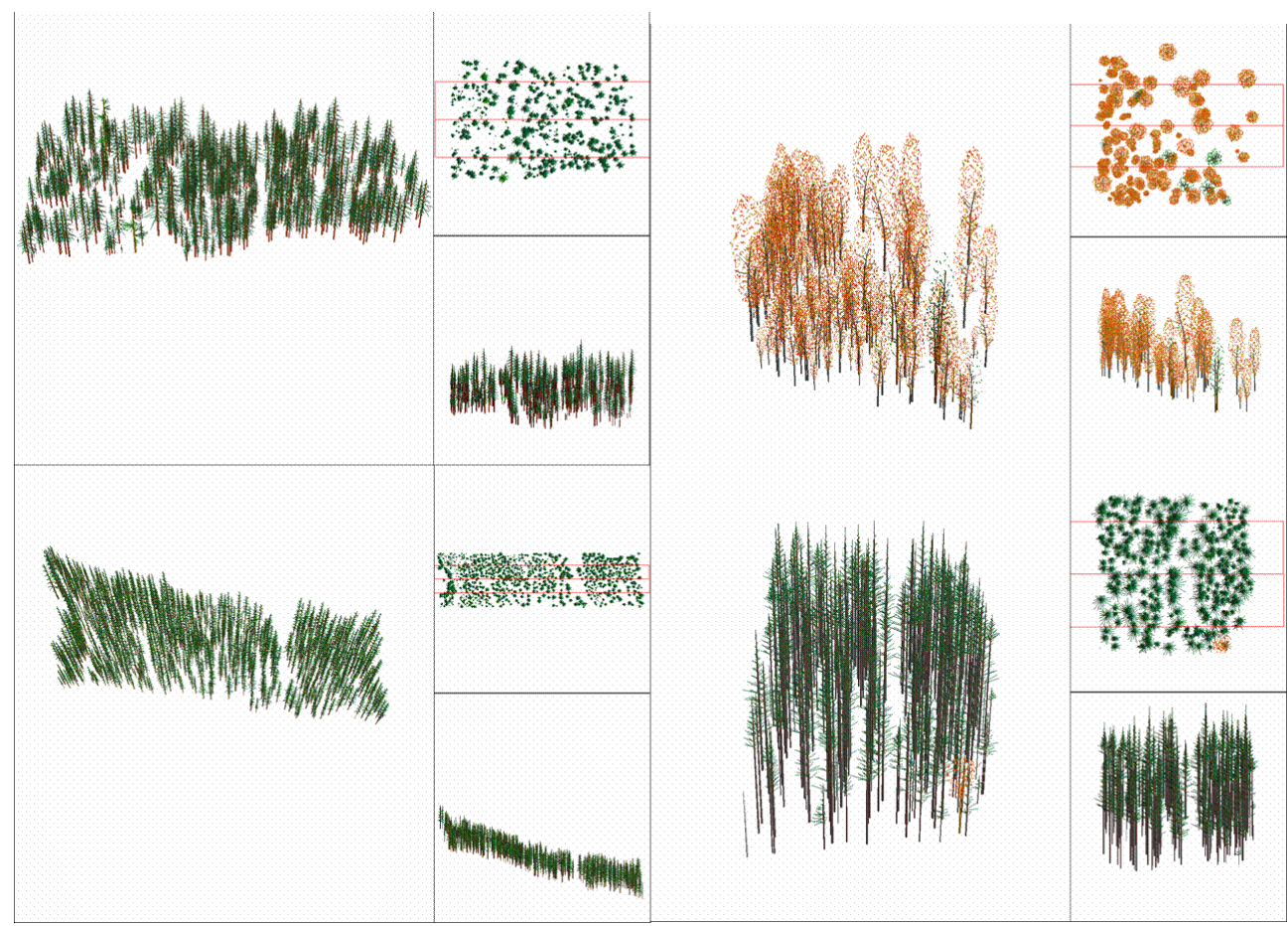

Figure 7. Schematic representations of 4 of the 9 marteloscopes implemented during the MANFRED project : Verbier (Spruce stand, CH), Solcava (Beech stands, SI), Valdrôme (Austrian black pine stand, F), Gashurn (Spruce stand, AT).

\section{The probable consequences of climate change on protection forest}

Snow avalanche occurrences are driven by 3 types of parameters: meteorological factors, topographic conditions and land use types in the release zones. To observe a snow avalanche release it's necessary to have a certain amount of snow height, a weak layer in the snow cover and to for the snow mass to overshoot a critical stability equilibrium value. The total snow mass is determined directly by the amount of snow precipitation, the presence of strong winds, changes in temperature and rainfall, along with land use types in the release area. The presence of forest vegetation limits the snow deposit on the slope and also modifies the snow quality. The efficiency of snow interception by the forest canopy is correlated with tree species: broadleaf trees are less efficient than coniferous ones.

All of these parameters are directly influenced by the climate, and anthropogenic climate change thus will have an influence the frequency and severity of this hazard. The cumulative effects of possible climate variable changes (temperature, precipitation, wind...) on the release conditions of snow avalanches need to be evaluated. Until now, few studies are available on this subject. The two foremost studies have been performed within the Interreg Alpine Space project CLIMCHALP [12] and by the Cemagref [13]. 
The main results of these studies are 1) that there is no statistical correlation between the number of events and the evolution of the climate over the last century, 2) globally, experts agree that under warming climate conditions the snow cover stability will tend to increase, 3 ) observations show that over the past 30 years, snow avalanches have tended to stop at higher altitudes than usual, but for extreme events no differences in stopping altitude have been recorded.

Rockfall occurrences are also driven by 3 types of parameters: meteorological factors, topographic conditions and geology. One of the main parameters is the freeze-thaw-cycle. These cycles are directly related to weather conditions: high variation of temperature over a short time period, and duration and intensity of precipitation. In fact, the only certain change will be a temperature increase. The most probable consequences of climate change on rockfall will be the increase in occurrence. Up to now this trend has not been proven but some studies indicate an increase in rockfall occurrences for years with weather anomalies. The graph below shows recorded rockfall events from 1989 onwards in the French department of Haute-Savoie. The year 1999 is characterized by a strong winter and 2003 by a severe drought. These two years have the greatest number of recorded events (21 and 19 respectively) for the period 1989-2006. Between 1999 and 2004 the number of events is greater than the average number of occurrences. This is probably due to the consequences of the climatic conditions of the winter of 1999 on the stability of the geological facies.

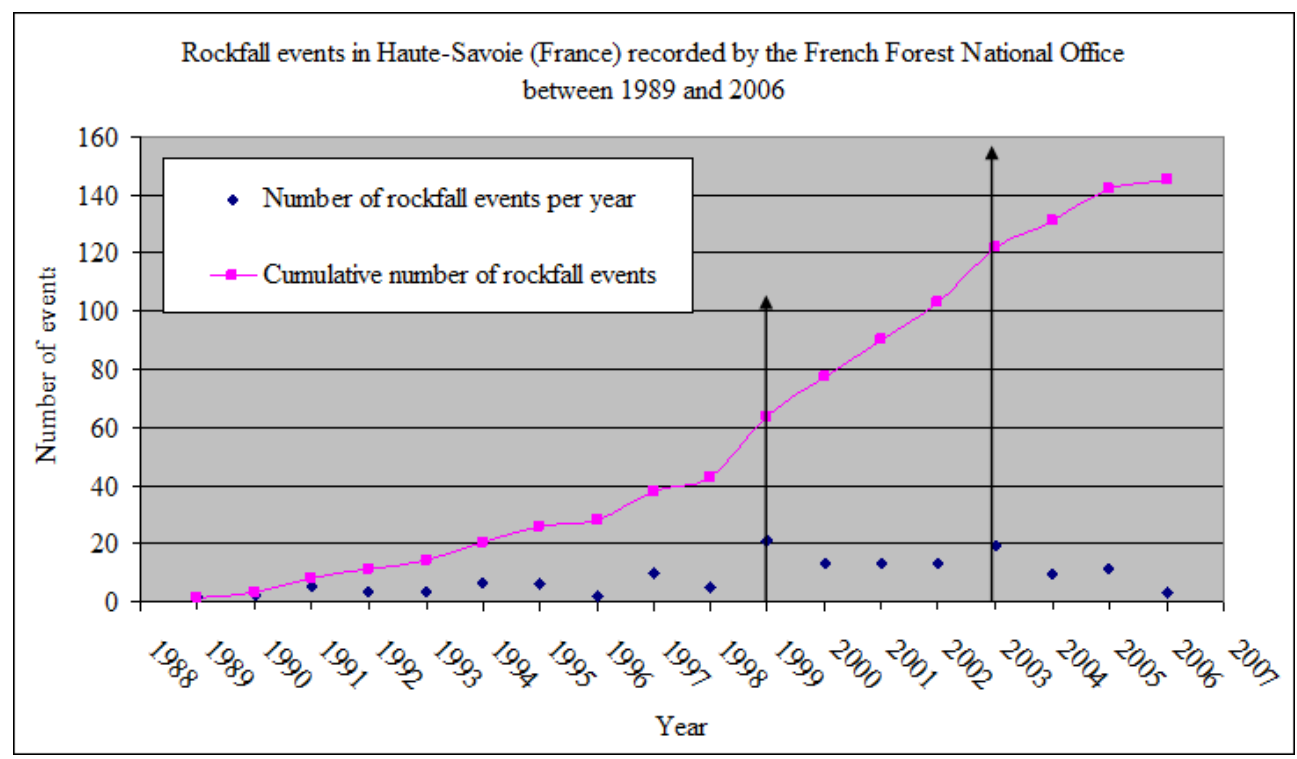

Figure 8. A chronology of the number of recorded rockfall events during the period 1989 - 2006 for the French Department of Haute-Savoie. 
There is general consensus within the scientific community that climate changes will impact forest vegetation in 3 major ways:

- An upward attitudinal (and elevation shift) of the forest timberline and a shift in the distribution of species (already observed within Europe)

- An increase in forest growth (already observed within Europe)

- An increase in the development and impacts of pests and diseases

The study of the potential changes in tree species geographic distribution in the Alpine space has been provided by the MANFRED project. These distributions have been formalized via the probability of presence of tree species on 1x1 km raster maps. For the main tree species (Fagus sylvatica, Picea abies, Abies alba, Pinus nigra and Pinus sylvestris), and for the project's pilot areas for which the mapping of the protection forest has been completed, an analysis of the consequences of the evolution of the tree species distributions on the forests' protective function has been processed. The main conclusion of this study is that there will be an increase in the surface covered by forests potentially providing efficient protection against rockfall propagations and snow avalanche releases. This is due to 3 factors:

1. broad-leaf trees will progress upslope covering rockfall propagation areas previously covered by coniferous forests,

2. the coniferous trees will also progress upslope covering snow avalanche releases area currently not covered by forest,

3. there will probably be a transition step during which the snow avalanche release zones currently covered by coniferous forests will be covered by mixed forests, where these mixed forests will create conditions for efficient protection.

For the French departments of Haute-Savoie and Isère, the increase in protection forest will be $23 \%$ and $19 \%$ respectively, for rockfall, and $28 \%$ and $24 \%$ for snow avalanches (see Figure 9).

Due to these results, the most probable consequences of forest evolution in the field of snow avalanches and rockfall prevention are that:

- Over the next 100 years, the progression of broad-leaves vs. coniferous may decrease the current protective effect of mountain forests against snow avalanches to a minor extent. The snow interception of broad-leaf canopy is less than for a coniferous one; however, there will likely be a buffer zone characterized by the presence of mixed forest. This buffer zone will probably provide efficient protection if broad-leaves trees represent less than $30 \%$ of the forest canopy.

- The progression of broad-leaf vs. coniferous trees might increase the protective effect of mountain forests against rock falls. Broad-leaf trees have higher mechanical resistance to impact on their trunks than coniferous trees.

- The natural response of vegetation to an increase in temperature will be an attitudinal migration. Each degree of temperature increase will correspond to migration of $150 \mathrm{~m}$ in altitude. Currently non forested snow avalanche release zones might be, in the future, 

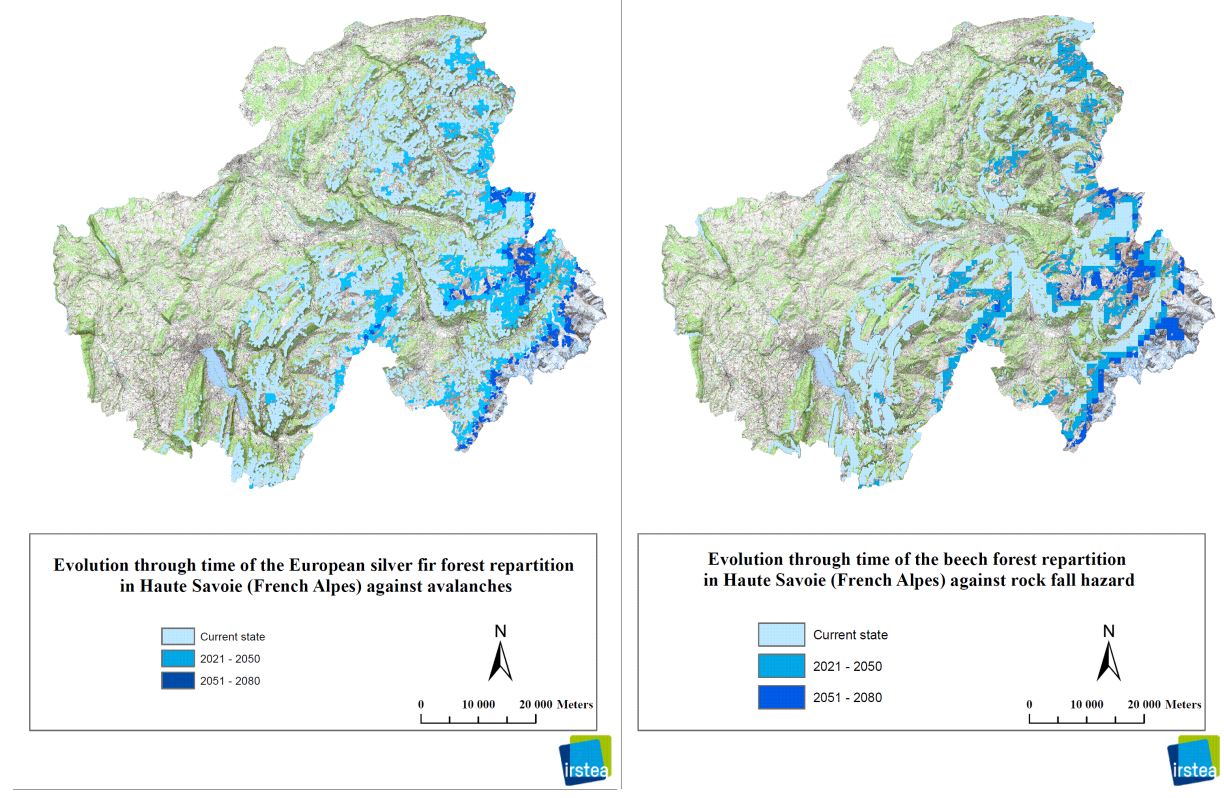

Figure 9. The evolution (2010 - 2080) for the French Department of Haute-Savoie of the geographic distribution of Picea abies in snow avalanche release zones and Fagus sylvatica in rockfall propagation zones. Light blue: zones covered in 2010, medium blue: zones covered as of 2050, dark blue: zones covered as of 2080.

covered by forest vegetation. If it's the case then these zones could be stabilized and fewer releases might be observed.

- By the end and due to these probable consequences, the major conclusion is that in the next 100 years the protection function of mountain forests will increase.

\section{Conclusion and discussion}

Because of the uncertainty of the climate change development foresters have to deal with new situations, which for protection forest management are not so easy to foresee. In fact the only certain changes will be the temperature increase and the modifications of the tree species geographic distribution. The results of the project Manfred show that the protection function of mountains forests will probably increase within the next century. For rockfalls mitigation, this protective effect will increase due to the progression on the upper slopes of broad-leaves trees ones. For snow avalanche mitigation, this protective effect will increase due to the colonisation of new releases zone by coniferous trees.

The complementary approaches developed within the Manfred project, the field observations, robust data acquisition, real size tests, synthesis of guidelines and modelling have proven to 
be an excellent basis for both research on the interaction between geo-hazards and protection forests and on the impact of climate changes on this function, as well as for the development of tools that are relevant for practitioners working in the field of natural hazard and risk management. With the help of the data and tools, we have been able to show that forests have the capacity to provide a degree of protection that is comparable to many other technical measures. They offer therefore possibilities for using mixed ecological and technical solutions for snow avalanches and rockfalls hazards management. It all depends on the characteristics of the phenomena (size of the release zone, size and energy of the boulders...), the length of the forested slope between release area and the elements at risk, and the structure of the forest. The protective effects of trees and stands can be very well quantified with the latest generation 3D simulation models (currently operational for rockfalls and under development for snow avalanches) that use Airborne Laser Scanning data both for mapping the forest and the terrain. Based on those analyses, the efficacy of the forest might be improved over the years by using the latest knowledge, as the tables of recommendations provided by the project Manfred, on protection forest management which includes the mentioned eco-engineering techniques.

\section{Acknowledgements}

This chapter is an outcome of the Interreg project Manfred, conducted within the Alpine Space programme.

\section{Author details}

Frédéric Berger ${ }^{1 *}$, Luuk Dorren², Karl Kleemayr ${ }^{3}$, Bernhard Maier ${ }^{4}$, Spela Planinsek ${ }^{5}$, Christophe Bigot ${ }^{1}$, Franck Bourrier ${ }^{1}$, Oliver Jancke ${ }^{1}$, David Toe ${ }^{1}$ and Gillian Cerbu ${ }^{6}$

*Address all correspondence to: fredric.berger@irstea.fr

1 Irstea, National Research Institute of Science and Technology for Environment and Agriculture, Grenoble, France

2 FOEN, Federal Office for the Environment, Hazard prevention division, Bern, Switzerland

3 BFW, Federal Research and Training Centre for Forests, Natural Hazards and Landscape, Department for Natural Hazards and Alpine Timberline, Innsbruck, Austria

4 Stand Montafon, Forest division,Schruns, Austria

5 Slovenian Forest Institute, Ljubljana, Slovenia

6 FVA, Forest Research Institute of Baden-Wuerttemberg, Freiburg, German 


\section{References}

[1] European Observatory of Mountain Forests 2000

[2] Swiss Federal Statistical Office 2002

[3] BUWAL Bundesamt für UmweltWald und Landschaft. Lawinenwinter 1998/1999. Bern, Switzerland; (2001).

[4] Brang, P, Schönenberger, W, Frehner, M, Schwitter, R, Thormann, J. J, \& Wasser, B. Management of protection forests in the European Alps:an overview. For. Snow Landsc. Res. (2006). , 80, 23-44.

[5] Rey, F. Ecological engineering and engineering ecology: the case of rehabilitation of severely eroded mountainous catchments. Ecological engineering (accepted to be published in (2013).

[6] Heim, A. Bergsturz und Menschenleben. (1932). Beiblatt zur Vierteljahrsschrift der Naturforschenden Gesellschaft in Zürich, Fretz \& Wasmuth, p., 77

[7] Lied, K, \& Bakkehoi, S. Empirical calculations of snow-avalanche run-out distances based on topographic parameters.(1980). Journal of Glaciology, , 26(94), 165-176.

[8] Frehner, M, Wasser, B, \& Schwitter, R. Nachhaltigkeit und Erfolgskontrolle im Schutzwald- Wegleitung für Pflegemassnahmen in Wäldern mit Schutzfunktion. Bern: Bundesamt Umwelt Wald Landschaft. (2005). p.

[9] Compagnia delle Foreste Sr.l. : Selvicoltura nelle foreste di protezione. Esperienze e indirizzi gestionali in Piemonte e Valle d'Aosta. (2006). 139-7-88890-122-3

[10] Gauquelin, X, et al. Guides des sylvicultures de montagne- Alpes du nord françaises. (2006). Cemagref, CRPF, ONF: 289 p.

[11] Dorren, L. K. A, \& Berger, F. Le Hir C., Mermin E., Tardif P.: Mechanisms, effects and management implications of rockfall in forests.(2005). For. Ecol. Manag., 215, 1-3:183-195.

[12] www.climchalp.org

[13] Eckert, N, Deschatres, M, \& Bélanger, L. Analyse des fluctuations spatio-temporelles des nombres d'avalanches dans les Alpes du Nord à partir de l’EPA. (2010). Sciences Eaux \& Territoires,, 02, 16-25. 